\title{
Shifting the culture of lab animal care
}

\author{
Cindy Buckmaster, PhD, CMAR, RLATG, Director, Center for Comparative \\ Medicine, Baylor College of Medicine, Houston, TX.
}

\begin{abstract}
Dr. Buckmaster talks about her passion for developing more compassionate approaches to caring for animals and the importance of visibility for the lab animal community.
\end{abstract}

What made you decide to pursue a PhD after teaching high school and collegelevel science for 6 years?

I enjoyed teaching and loved the kids, but I wanted to learn more. I've always been fascinated with the brain and the biology of behavior. SUNY Stony Brook was nearby, so I called a professor in the Neurobiology and Behavior department and explained to him my interests. He said there was a new group from California joining them that studied learning and memory and invited me to come meet them. Soon afterward, I was accepted to the $\mathrm{PhD}$ program.

You worked with non-human primates throughout your research career. How did those experiences contribute to your interest in lab animal science? They had everything to do with it. I spent a lot of time bonding with my animals. They became pretty outgoing, and when you entered the room, most would come forward to greet you or steal something from you. Keys were their favorites! When I visited other animals they appeared bored and timid, and it really bothered me. The quality of life that went beyond their husbandry and veterinary needs seemed to be missing. Many of the animal technicians assumed a fairly detached approach to their animals' care because the emotion they felt was not validated by their leaders. I felt intensely compelled to change this mindset.
You are currently the Director of the Center for Comparative Medicine at Baylor College of Medicine. Describe how your typical workday now is different from when you worked as a trainer for animal care personnel.

My job is the same in that I've been privileged to have opportunities to shift our culture away from the old-school model of detachment toward one that encourages compassion and validates emotion. As a trainer, I incorporated this shift in culture into lessons and SOPs. I have a broader influence as Director, working with our researchers and training and leadership team to continue to shape this cultural change and demonstrate its value in our work. We work together to improve the quality of life for everyone. What's better than that?!

You have called for a campaign of visibility from the lab animal science community. Why is this issue so important to you?

Everything we do is defined by love and compassion for our animals and everyone who benefits from the life-changing work they support. Animal-based research is deeply misunderstood by the public, and the philosophy of sticking our head in the sand and not talking about what we're doing has supported this misunderstanding. The activists are waging a campaign with the public that is based in emotion, while most of our responses are grounded in reason. We go on and on about why our work is important and how it improves lives, and half of Americans still do not support us. That's because that isn't what they want to

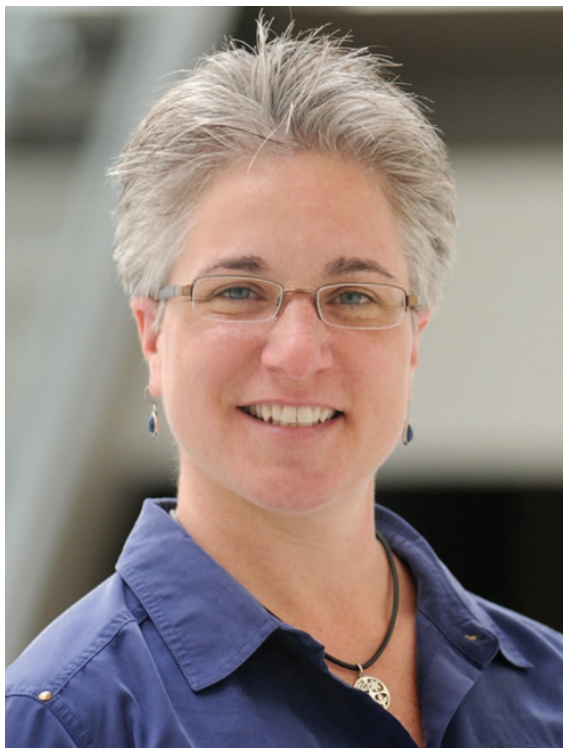

know. What they really want us to tell them is that the activists are lying to them about how we feel about our animals. They want to know that we value and care about them. They want to know that we treat them with compassion and respect, and they need to know that our work is a labor of love for all living things. The selfless nature of this love is extraordinary and uncommon; we are heroes.

As society learns who we are, through conversations and images depicting our expertise and compassion, the activists' claims will lose validity. We don't have to argue with them; all we have to do is share our truth. Every time I meet someone who asks me what I do, I tell them about our technicians and their devotion to our animals. I tell them about the special relationships they develop with our animals and the grief they experience when they're gone. And I tell them that they do all of this because they love animals and people. Some of them cry. Some of them hug me. All of them thank me for making them feel better about our work. That's really the shift in the culture I'm trying to effect, and that shift will change everything. 